\title{
Life Cycle Greenhouse Gas Analysis of Biojet fuels with a Technical Investigation into their Impact on Jet Engine \\ Performance
}

\author{
Lead \& Correspondence Author \\ Kadambari Lokesh MSc \\ Doctoral Researcher, Dept. Power and Propulsion, \\ School of Engineering \\ Cranfield University \\ Cranfield, Bedford, \\ MK43 OAL \\ United Kingdom \\ E: k.lokesh@cranfield.ac.uk \\ Vishal Sethi \\ Lecturer \\ Cranfield University \\ E: v.sethi@cranfield.ac.uk \\ Theoklis Nikolaidis \\ Lecturer \\ Cranfield University \\ E: t.nikolaidis@cranfield.ac.uk \\ Eric Goodger \\ Lecturer \\ Cranfield University \\ E: egoodger@waitrose.com \\ Devaiah Nalianda \\ Research fellow \\ Cranfield University \\ E: devaiah.nalianda@cranfield.ac.uk
}

\section{ABSTRACT}

Biojet fuels have been claimed to be one of the most promising and strategic solutions to mitigate aviation emissions. This study examines the environmental competence of Bio-Synthetic Paraffinic Kerosene (Bio-SPKs) against conventional Jet-A, through development of a life cycle GHG model (ALCEmB- Assessment of Life Cycle Emissions of Biofuels) from "cradle-grave" perspective. This model precisely calculates the life cycle emissions of the advanced biofuels through a multidisciplinary study entailing hydrocarbon chemistry, thermodynamic behaviour and fuel combustion from engine/aircraft performance, into the life cycle studies, unlike earlier studies. The aim of this 
study is predict the "cradle- grave" carbon intensity of Camelina SPK, Microalgae SPK and Jatropha SPK through careful estimation and inclusion of combustion based emissions, which contribute $\approx 70 \%$ of overall life cycle emissions (LCE). Numerical modelling and non-linear/ dynamic simulation of a twin-shaft turbofan, with an appropriate airframe, was conducted to analyse the impact of alternative fuels on engine/ aircraft performance. ALCEmB revealed that Camelina SPK, Microalgae SPK and Jatropha SPK delivered $70 \%, 58 \%$ and $64 \%$ LCE savings relative to the reference fuel, Jet-A1. The net energy ratio analysis indicates that current technology for the biofuel processing are energy efficient and technically feasible. An elaborate gas property analysis infers that the Bio-SPKs exhibit improved thermodynamic behaviour in an operational gas turbine engine. This thermodynamic effect has a positive impact on aircraft-level fuel consumption and emissions characteristics demonstrating fuel savings in the range of $3-3.8 \%$ and emission savings of $5.8-6.3 \%\left(\mathrm{CO}_{2}\right)$ and $7.1-8.3 \%(\mathrm{LTO} \mathrm{NOx})$, relative to that of Jet-A.

\section{KEYWORDS}

Bio-SPKs, Life cycle emissions, Engine/ Aircraft performance, Thermodynamics, Numerical modelling

\section{INTRODUCTION}

In 2007, the International Panel for Climate Change (IPCC) quoted civil aviation to be "one of the fastest growing means of transport" [1] \& [2]. Civil aviation, amidst this growth, is obligated to reduce its environmental impact through every possible means. Present fleet of aircraft are $70 \%$ more fuel efficient than 40 years ago. Since then, the environmental and economic significance of emission-conscious air-traffic management (ATM) strategies and route optimisation have been realised. Global implementation of modernised ATMs could economise time, emissions and costs. From a commercial point of view, incessant demand for air travel is the foremost hurdle to improving the environmental standards of civil aviation. Research and development into emission control technologies and GHG-conscious air traffic management have significantly contributed to greener aviation. For example the "Perfect Flight Initiative" by Airbus in collaboration with Air Canada in 2012 and Air France in 2011 using A319 and A321 achieved close to 40\% and 50\% reduction in $\mathrm{CO}_{2}$ emission respectively. These reductions were achieved through improvised 
aircraft efficiency, ATM and use of advanced biofuels [3]. Further developments in design reconfiguration and operations brings in trade-off difficulties which pose restrictions to the design space exploration. The aviation sector is, therefore, keen to explore other radical options including sustainable alternative fuels that are claimed to be "promising solution" by ACARE (Advisory Council for Aviation Research and Innovation in Europe), provided their sustainability and feasibility can be demonstrated from their life cycle perspective [4].

This study is devoted to evaluating the environmental performance of three chosen "drop-in" advanced biojet fuels (Advanced biofuels are "second generation" that do not compete with food crops for arable land) against conventional Jet Kerosene. It is achieved through development of a holistic life cycle model called ALCEmB (Assessment of Life Cycle Emissions of Biofuels) which captures the carbon intensity of the Bio-SPKs from the point of raw material generation to the point of fuel combustion (cradle-grave). The biojet fuels chosen for this analysis are Camelina SPK, Jatropha SPK and Microalgae SPK which are collectively called as Bio-SPKs. Bio-Synthetic Paraffinic Kerosene (Bio-SPK) is plant derived lipid which is thermochemically tailored by a process called "Hydroprocessing", to compositions similar to conventional jet fuel, thus ensuring compatibility with the existing engine scheme. Owing to their ability to deliver similar / better fuel and engine performance, they are claimed as "drop-in". The chosen advanced biofuels offers broader coverage of processing techniques which is dictated by their morphological characteristics and cultivated geographical locations (impact on the feedstock's carbon intensity). In addition to the quantifications of Life Cycle Emissions (LCE), this study reports the energy intensity of the candidate biofuels through Net Energy Ratio (NER) evaluation. Owing to the uncommercial nature of the biofuel candidates, such life cycle studies are bound by uncertainties. These uncertainties have been handled resolved with carefully considered assumptions suggested by earlier studies and industry experts. Besides process based emissions, this paper aims to predict aero-engine based emissions through use of numerically modelled engine/ aircraft systems and computational simulation of a mid-range mission with the model aircraft, operated on candidate fuels, which contributes to the "cradle-grave" carbon footprinting of the Bio-SPKs.

According to ASTM (American Society for Testing and Materials) D7566 for renewable jet fuels use, the physico-chemical and hardware compatibility specification of candidate fuels restrict their 
use to $50 \%$ blends with conventional jet fuel in existing aero-engines [Table 1]. However, some test flights with $100 \%$ Camelina and Algae derived biofuels operated, on new fleet of business jets and turboprop engines respectively. This milestone marks the dedication of the aviation industry towards a more sustainable and greener growth [5] \& [6], thus setting the context for this analysis. It is therefore, essential to note that this study evaluated the environmental competence of $100 \%$ pure biofuels.

An elaborate technical investigation was conducted to evaluate the thermodynamic influence of each of the biofuel candidates on gas turbine performance which was extended to a realistic mission analysis through numerical modelling and computational simulation. The performance based impact of each of the biofuel candidates on the chosen engine/airframe configuration was measured in terms of fuel consumed $(\mathrm{kg})$ and interpreted to mission based emissions $\left(\mathrm{CO}_{2}\right.$ and NOx). Fuel-effects on a chosen engine/airframe configuration was assessed from a user-defined mid-range mission established over a range of $4650 \mathrm{~km}$, a typical flight distance between destinations, London Heathrow (LHR) and Bahrain International (BAH).

\section{LITERATURE REVIEW}

Life cycle emission assessments of Camelina SPK [7], [8] \& [9] Microalgae SPK [10], [11], [12] \& [13] and Jatropha SPK [14] and [15] have been conducted earlier. These studies were elaborately focussed on the GHG emission attributable to the life cycle processes of biofuels (renewable diesel and hydrotreated renewable jet fuel). However, these studies were isolated and specialism specific. ALCEmB aims to standardize life cycle stages (production metrics for life processes and integration of system level emission prediction), unlike earlier studies, where the adopted combustion emissions were assumed figures.

Biomass credit is a measure of carbon savings delivered by the biofuel plantations through natural carbon fixation (photosynthesis). The biomass credit is generally assumed to be equivalent to the amount of $\mathrm{CO}_{2}$ wake emissions as observed in a number of studies [8], [10], [12] and [16]. Feedstock-specific quantification of the biomass credit is, however, crucial to ranking the biofuels based on their carbon intensity. Unlike earlier studies where assumptions were adopted, ALCEmB 
aims to precisely predict the feedstock-specific biomass credit through incorporation of hydrocarbon chemistry and tracking carbon cycle within the life cycle processes.

Carbon intensity from freshwater consumption (one among the key criteria for competition with food crops) is generally overlooked or not reported in most LCA studies owing to the lack of data or use of LCA software which may innately calculate this parameter [8], [10], [12] \& [16]. GHG emissions related to water supply is assumed to be energy-demand dependent, especially with the type of fossil fuel use for energy generation, to lift ground water to surface. In addition to the above mentioned, ALCEmB predicts carbon intensity attributable to the water consumptions unlike earlier studies [9], [10], [11], [12] and [15]. Further details have been elaborated in the sub section 3.2.1.

The uncommercial nature of the biojet fuel types (Bio-SPKs) analysed in the earlier studies led to the use of emissions attributable to the reference fuel, Jet-A, towards analysis fuels. For instance, most studies have adopted transportation (feedstock /fuel product) based emissions attributable to Conv. Jet fuel for the biofuels as well [9], [10], [12] \& [15]. When the $\mathrm{CO}_{2}$ equivalents of GHG emissions is measured as $\mathrm{g} \mathrm{MJ}^{-1}$ of fuel (the functional unit of this study), adoption of standardised emission figures neglects the fuel's energy factor thus affecting the fidelity of this study. ALCEmB aims to use fuel-specific properties and composition to predict LCE through underpinning lifeprocess and engine/aircraft system based investigations.

Systemic investigation of the $100 \%$ Bio-SPKs entails virtual experimentation through non-linear simulation based on their thermodynamic systemic behaviour. The importance of fuel characteristics becomes significant, especially in aero-engine applications as it defines the airline industry's sensitivity to the two main factors: techno-economical and passenger safety considerations. There are inter-continental authorities that establish standards and specifications for commercial aviation fuel upon extensive visual, laboratory and site based evaluation of conventional and alternative fuel candidates e.g. ASTM (American Standard for Testing and Materials) and DEF-STAN (UK Defence Standards).

Bio-SPK (also known as Hydrotreated Renewable Jet (HRJ)), is synthesised through Hydroprocessing, a process where the plant lipids are pressurised with excess hydrogen, in the presence of a multifunctional catalyst, at varying temperature and pressure conditions. This process consequentially improves the hydrogen content of the final jet fuel, thus boosting its 
calorific value. It is essential to note that variation in the performance and thermal properties of the Bio-SPKs, discussed in the upcoming section, are in relation to their fossil-derived counterpart, JetA. An increase in the hydrogen content of the fuel is likely to reduce fuel density which in turn is expected to exhibit thermodynamic variations. In-depth evaluation of Bio-SPKs performance based fuel properties can be comprehended only through bench-test and experimental analysis. However, a qualitative attempt to appreciate the effect of fuel properties on the systemic components has been made in section 4.1 and Appendix I. This purpose of this investigation is to gain an insight about the physical and thermal fuel effects of Bio-SPKs on an operating aero-engine.

\section{METHODS}

\subsection{Estimation of Bio-SPK composition}

A fundamental pre-requisite to any fuel-centred analysis is the identification of appropriate fuel composition. The empirical composition and the molar mass were numerically estimated from the carbon distribution data available in open domain [17], [18] \& [19]. Bio-SPKs are composed of paraffin ( $\mathrm{n} \&$ iso) ( $99 \%$ by mass), cyclo-paraffin ( $0.9 \%$ by mass) and aromatics ( $0.2 \%$ by mass), predicted through gas chromatography (GCxGC) in accordance to D6379 of ASTM specification for fuel testing and graphically presented in [Figure 1]. In general, the hydrocarbon construct of a paraffinic carbon species in a fuel is represented as

$$
=a+(2 b+2)
$$

where, $\boldsymbol{a}=$ no of carbon atoms in a paraffinic species and

$$
\boldsymbol{b}=\text { no of hydrogen atoms in the paraffinic species }
$$

Insert Figure 1

The total paraffinic weight and eventually the molecular mass of each of the biojet fuel can, therefore be calculated from their carbon spectra using the following method. The molar mass of each of the Bio-SPK is calculated from,

$$
\begin{aligned}
& d=[c \times a] \\
& e=[c \times b]
\end{aligned}
$$


where, $c=$ mass fraction of the specific paraffinic species, $g$

$d=$ Carbon component of a specific paraffinic species

$e=$ Hydrogen Component of a specific paraffinic species

To calculate the empirical formula $\left(\mathrm{C}_{\mathrm{x}} \mathrm{H}_{\mathrm{y}}\right)$ of the each of the Bio-SPKs

$$
\text { Carbon no. }(x)=\sum(c \times a)
$$

$$
\text { Hydrogen no. }(y)=\sum(c \times b)
$$

Molar (molecular) mass (Mm) of each of the Bio-SPKs can be calculated using the approach provided in Eq 6

$$
M m=[12.01(x)+1.008(y)]
$$

where, $\mathbf{M m}=$ Molecular mass of Bio-SPK $\left(\mathrm{g} \mathrm{mol}^{-1}\right)$

[Note: 12.01 and 1.008 correspond to the atomic mass of Carbon(C) and Hydrogen $\left(\mathrm{H}_{2}\right)$ respectively].

The calculations have been elaborated in Appendix A- Appendix F of the supplementary section. Precise estimation of hydrocarbon composition of Camelina SPK, Jatropha SPK and Microalgae SPK is crucial to the upcoming assessment which entail the gas property prediction and analysis of the candidate fuels. This data defines the performance properties of the given fuel in a numerically modelled and validated engine/aircraft system. Such an analysis aims to provide an insight into their thermodynamic influence on an aero-engine performance and emission characteristics [17], [20] \& [21]. The empirical data and key performance properties of each of the $100 \%$ Bio-SPKs has been presented in Table 1. Combustion characteristics including stoichiometric fuel/air ratio, adiabatic flame temperatures, essential for fuel combustion and subsequent emission studies were also determined using methods stated by Goodger \& Ogaji [22] which in turn demands the knowledge of empirical information of the fuel type in question.

Insert Table 1

\subsection{Life Cycle processes of Bio-SPKs}

Life cycle assessment is an effective tool which can be implemented to study the environmental, economic impacts coupled with the energy intensity of a given product, from a stage-stage perspective. LCE of Bio-SPKs will be assessed through use of ALCEmB and weighed against the 
fossil derived reference counterpart, Jet-A [the life cycle emissions of which have been presented in Appendix $\mathrm{H}$ ]. However, it is essential to define the four elements of an LCA in relation to this analysis.

Goal and Scope: The system boundary for this analysis has been defined in Figure 2. The scope of this study also includes the product consumption aspect of LCA (fuel combustion) which is generally counted as avoided emissions and a figure is assumed [9], [12], [16] \& [23]. An elaborate account of $100 \%$ Bio-SPK behaviour within a modelled and validated engine/ aircraft system with the operation based emissions will be included in this environmental impact analysis. The $\mathrm{CO}_{2}$ and NOx emissions released from a mid-range mission will also be predicted based on estimated engine emission index and predicted fuel consumption data. This technical investigation is facilitated through use of a gas turbine/ aircraft performance simulation code operating on FORTRAN platform. Further details will be discussed in section 3.2.6.2 and 3.2.6.3.

\section{Insert Figure 2}

Inventory Analysis: Quantified material inputs (fertilizer, water and nutrient), energy inputs (fossil derived energy) associated with the production of Bio-SPKs have been integrated into this life cycle study (Table 2). The material and energy input have been evaluated with the energy specifications of the each of the Bio-SPKs. Owing to the non-commercial nature of Bio-SPKs, uncertainties have been identified and dealt with the use of appropriate assumptions. Identification of system boundary is a pre-requisite of any LCA. Energy demands of Bio-SPKs synthesis have been documented for each and every stage. Net energy ratio (NER), the ratio of total energy produced to total energy consumed, defines the technical feasibility of a given product and is presented in section 4.11 .

Insert Table 2

Impact assessment: The anthropogenic GHGs incur a direct irreversible impact on the environment through the greenhouse effect, the quantification of which is, therefore, essential. The $\mathrm{CO}_{2}$ equivalents of $\mathrm{GHG}$ emissions are measured as $\mathrm{g} \mathrm{MJ}^{-1}$ of the given fuel and is also the functional unit of this analysis. This unit is enables one to weight the $\mathrm{CO}_{2}$ emission equivalents from GHG emissions, per unit energy content for the given fuel. The $\mathrm{CO}_{2}$ equivalent metrics have 
been calculated using the global warming potential factors for each of the $\mathrm{CO}_{2}, \mathrm{CH}_{4}$ and $\mathrm{NOx}$ which are 1, 25 and 298 respectively [1] [Equation 6]. It is essential to note that this study primarily focuses on the fuel product and the by-products have been neglected for the purpose of simplicity.

$$
\begin{array}{r}
\text { Life Cycle emissions }\left(\mathrm{gMJ}^{-1}\right)=\mathrm{CO}_{2}+\left(\mathrm{N}_{2} \mathrm{O} \times G W P_{\mathrm{N}_{2} \mathrm{O}}\right)+\left(\mathrm{CH}_{4} \times \mathrm{GWP}_{\mathrm{CH}_{4}}\right)+ \\
\mathrm{CO}_{2_{\text {wake }}} \mathrm{Eq} 7
\end{array}
$$

Interpretation of results: Predicted "cradle-grave" emissions of Bio-SPK will be weighed against the reference fuel, Jet-A to identify any environmental benefits / concerns associated with them.

Co-product Allocation: Systems boundary of ALCEmB begins from biomass cultivation (cradle) to wake emissions (grave) and follows energy based emission allocation as baseline scenario. Mass based emissions allocation has been conducted and presented in section 4.11. Due to the uncommercial nature of the biofuels dealt in this analysis and lack of information on supply capacity, market based and displacement allocation has been omitted in this analysis.

\subsubsection{Biomass Cultivation}

Camelina: Camelina is assumed to be sustainably grown through crop rotation with Winter Wheat in Montana, USA, owing to practice of continuous Camelina crop improvement and expansion close to tens of thousands of hectares [26]. Besides resistance to winter season, Camelina, with its lessened need for nutrients, additionally improves the soil quality towards the next batch of winter wheat cultivation [9]. Camelina utilizes reduced amounts of soil moisture for its growth thereby decreasing its need for water supply and subsequent emissions. Energy consumption is contributed by the use of diesel in equipment for land preparation, and electricity costs towards operation of facilities standardised for a hectare of land. The energy intensity of water supply by pumping ground water to surface is measured as water supply emissions. NER (Net Energy Ratio), which is simply the ratio of energy fed into a process/product to the energy deliverable by the process/product, has been predicted for fuel specific life processes in order to quantify their energy efficiency over the annual production process.

Microalgae: Microalgal biomass was assumed to be cultivated in raceway ponds owing to their simplicity in operations and cost. The site of production is assumed to be in Southern India owing 
to a number of well-balanced factors including humidity, temperature cycles, availability of vast areas of non-arable land and ever-increasing interest in algae derived alternative energy. The algal culture will be constantly circulated through use of electrically operated paddle wheel. The algal strains which can serve as potential biofuel feedstock include Botryococcus sp, Chlorella sp and Chlamydomonas sp. A continuous supply of nutrients is supplied to the culture and with $\mathrm{CO}_{2}$ bubbled into the medium in the form of gas mixture (e.g. $3 \%$ by vol of $\mathrm{CO}_{2}$ and $97 \%$ by vol Air rather than $100 \%$ air) [27]. An average requirement of $\mathrm{CO}_{2}$ supply for algae ranges from $2.18 \mathrm{~kg} \mathrm{~kg}$ ${ }^{1}$ of dry algae grown as reported by some studies [10], [16] and [27].

Jatropha: Jatropha curcas is assumed to be cultivated in India due to ideal weather conditions, present commercial implementation and existing plantations covering 9000 ha of wasteland. The soil type chosen for cultivation is assumed to be of average quality to reduce the plantation's impact on land usage. GHG emissions from use of Urea were adopted from earlier studies [28] and [29].

Cultivation based assumptions and production metrics have been listed in Table 3. Assumptions on biomass cultivations and related productivity were adopted after careful consideration from earlier published literature [9], [11], [15] and [30].

Insert table 3

A method of predicting the water supply emissions based on the fossil energy source used and degree of energy demand has also be included in this study. According to Rothausen and Conway [31] and Nelson et al [32], lifting of $1 \mathrm{~kg}$ of water (assuming water density to be $1000 \mathrm{~kg} \mathrm{~m}^{-3}$ ) to $1 \mathrm{~m}$ at an efficiency of $100 \%$ using diesel as the power source produces $\mathrm{CO}_{2}$ equivalents of $0.665 \mathrm{~g}$. These above-mentioned specifications with the use of coal generated electricity produces $\mathrm{CO}_{2}$ equivalents of $3.873 \mathrm{~g} \mathrm{~kg}^{-1}$. The method of calculating energy consumption and emissions attributable to water supply has been presented in Equation 8 \& 9.

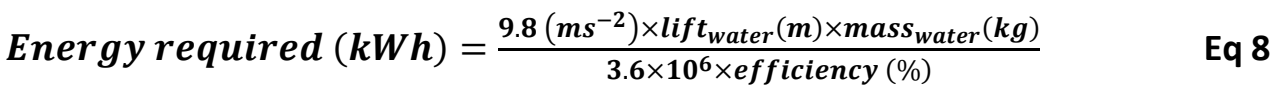

$$
\begin{aligned}
& \text { Net emissions }=\frac{\left[\mathrm{FDE}(\mathrm{kWh}) \times \text { Emissions }_{\mathrm{FDE}}\left(\mathrm{gCO}_{2} \mathrm{eq} \mathrm{kWh}^{-1}\right)\right] \times 1}{\text { LHV of Bio-SPK obtainable from } 1 \mathrm{ha}(\mathrm{MJ})}
\end{aligned}
$$




\subsubsection{Biomass Harvest}

Camelina: Camelina seeds are assumed to be harvested mechanically using low sulphur (LS) diesel operated equipment. The harvested seeds are assumed to be transported to the refining site which is integrated with bio-crude extraction facility. Harvest capacity of each of the biomass were calculated from their region specific actual production averages reported by earlier literature and the bio-crude density presented in Table 3 . It is essential to note that this principle of assumption on production capacity applies to the different biomass dealt in this study.

Microalgae: The algal biomass is assumed to be auto flocculated through $\mathrm{CO}_{2}$ starvation and concentrated by use of disc centrifuge which are considered as harvest techniques suitable for baseline allocation [10], [11], [16] \& [27]. The dewatering process of algal biomass is predominantly complex, energy intensive and depends on the structural morphology of the feedstock. FDE used to generate electricity to facilitate feedstock harvest was assumed to be natural gas and subsequent emissions have been appropriately calculated.

Jatropha: At the end of the maturation period (end of $2^{\text {nd }}$ year), the oil bearing seeds are manually collected [12] and transported to the refining facility for further processing.

\subsubsection{Feedstock and Bio-SPK Transportation}

Seeds/ biomass harvested are transported to the oil extraction and refining facility which were assumed to be located at a distance of $150 \mathrm{~km}$. The feedstock is transported through heavy truck freight with a vehicle mileage of $6 \mathrm{~km} \mathrm{~L}^{-1}$ and a freight capacity of 4 tonnes. A similar approach was adopted for the fuel product (Bio-SPK) transportation to the sites of storage/ consumption. Owing to the uncommercial nature of the Bio-SPKs, earlier workers have adopted the transportation emission for conventional jet fuel for the alternative fuels [10], [11], [12] \& [16] which contradicts with the consideration of energy dependent functional unit ( $\mathrm{g} \mathrm{MJ}^{-1}$ of fuel product) and addressed by ALCEmB in this analysis. 


\subsubsection{Bio-crude Extraction}

Camelina: The harvested seeds are assumed to be crushed by mechanical means at the initial stage. The crushed mix of seed and oil is subjected to hexane extraction in order to separate and degum the bio-crude. The $\mathrm{CO}_{2}$ footprint of hexane is $21 \mathrm{~g} \mathrm{~L}^{-1}$ of crushed oil and seed mix which were the result of vent losses encountered during the meal processing and solvent recovery process [33] \& [29]. According to Shonnard et al [9], the quantity of hexane used for oil extraction was $0.00125 \mathrm{~L} \mathrm{~kg}^{-1}$ of seeds harvested. On the other hand, mechanical press method of bio-crude extraction can also be employed. However the extraction efficiency of this process ranges between $70-80 \%$ depending upon energy demand and capacity of the press used and is less common due to its inability to equal the production capacity of its baseline counterpart and is more labour intensive [42] \& [54]. The energy requirement for this process was assumed to be $0.073 \mathrm{kWh} \mathrm{kg}^{-1}$ seeds.

Microalgae: The lipid content and composition are variable with the algal strain chosen for analysis. Therefore the downstream procedures will have to be customised to enable highefficiency lipid extraction. On the overall, microalgal feedstock is energy intensive at downstream processes due to their microscopic morphology. The harvested biomass is assumed to be sundried and subjected to chemical lysis with the lipid content harvested by hexane extraction. The extracted algal bio-crude, at this instance, contains hydrocarbons, lipids, fatty acids, alcohol, aldehydes and other trace elements. The energy and hexane use to boost extraction efficiency were assumed to be $0.02 \mathrm{kWh} \mathrm{kg}^{-1}$ and $0.016 \mathrm{~kg} \mathrm{~kg}^{-1}$ of biomass respectively.

Jatropha: Jatropha seeds are sundried, crushed and pressed through a screw press extruder is assumed to be $0.06 \mathrm{kWh} \mathrm{kg}^{-1}$ of seeds. The seeds were additionally subjected to hexane based oil extraction similar to the biomass discussed earlier to improve extraction efficiency to $90 \%$. A standard equation for the estimating total amount of bio-crude extracted from the biomass per yield per year has been presented in Equation 10.

Bio crude yield $(\mathrm{kg})=\left[\frac{\left(\frac{\text { Seed Yield }(\mathrm{kg}) \times \text { Seed oil content }(\%)}{100}\right) \times \text { Extract.efficiency }(\%)}{100}\right] \quad$ Eq 10

Total SPK yield $(\mathrm{kg})=\left[\frac{\text { Total Oil yield }(\mathrm{kg}) \times \text { Conversion efficiency }_{\text {Refining }}(\%)}{100}\right] \quad$ Eq 11 


\subsubsection{Hydroprocessing}

Degummed/ partially refined crude is hydroprocessed to renewable jet and other lighter fractions in the presence of excess hydrogen and a multi-functional catalyst at varying temperatures and pressures This study has adopted an industrial process devoted to synthesizing higher fractions of biojet fuel (67\%) among other by-products and this process is commercially called the Green Jet fuel process ${ }^{\mathrm{TM}}$, developed by UOP Honeywell for the stated purpose. Hydrogen requirement, in this study, is assumed to be synthesized through steam reformation of methane (40\%) (Natural gas) or by naphtha to gasoline reformation $(60 \%)$; routinely carried out in a petroleum refinery.

Hydrotreatment comprises of decarboxylation, decarbonylation and hydro-deoxygenation, selective hydrocracking and isomerization of bio-crude. The steps involved in Hydrotreatment of the biocrude have been obtained from industrial patents [18] \& [27]. Further details including reaction specifications of the renewable jet synthesis have been elaborated in Appendix G. However, the reaction specifications for Hydrotreatment has been presented in Table 4.

Insert Table 4

\subsubsection{Fuel Combustion}

\subsubsection{Fluid Thermodynamic Model}

Bio-SPKs are plant lipids which are thermochemically engineered to compositions similar to conventional Jet fuel. However, any discrepancies in fuel based performance properties is theoretically expected to have an effect on engine performance. The purpose of this study is to explore, identify and quantify these variations. The ALCEmB model integrates a module for quantification of fuel-specific systems operation-based emissions (fuel combustion emissions). A pre-requisite to such assessments is the development and designation of fluid property library consisting of the following parameters for each of the candidate fuels as a function of temperature, pressure and FAR [21] \& [36].

- Enthalpy (h)

- Entropy (s)

- Isobaric Specific heat $(\mathrm{Cp})$

- Density ( $\rho)$ 
- $\quad$ Gas constant (R)

CEA (Chemical Equilibrium with Applications) is a program developed by, then, NASA Lewis research centre (Ohio, Cleveland, US) for the prediction of fluid properties with industrially acceptable precision [37]. The fluid properties including Isobaric Specific heat, Enthalpy and Gas constant of combustion gases $(\mathrm{Cp}, \mathrm{h}$ and $\mathrm{R}$ respectively) were predicted using 7 - term functions through least square fit [38]. Predicted FTPs of the Bio-SPKs will be used to identify the fuel derived engine performance through empirical and numerical simulation. The thermodynamic variations between the alternative fuels and the reference fuel and thus its impact on gas turbine performance has been presented in subsection 4.9.1.

\subsubsection{Engine performance analysis}

Influence of the Bio-SPKs on engine performance was analysed through use of robust non-linear engine performance simulation. The performance is measured in terms of fuel consumption at varying flight modes which will be interpreted to quantities of pollutants $\left(\mathrm{CO}_{2}\right.$ and $\left.\mathrm{NOx}\right)$ on a pre-set flight profile.

For the purpose of analysing fuel-specific engine behaviour, a subsonic engine (CU-Jet) was virtually modelled from that of a baseline (CFM56-5B/2) [39] with available and assumed engine performance data. The engine modelling and behaviour were studied through a numerical gas turbine performance simulation code called TURBOMATCH, further information for which can be found on [40]. The purpose of this assessment was to comparatively measure an engine's fuel consumption operated with candidate fuels relative to the reference fuel and to identify any measurable variations. The operational parameters, for this analysis, were set constant (including ambient conditions, altitude, Mach no, engine speed, thrust output) for the different flight phases; take-off, cruise and climb. A general schematic of the modelled twin-shaft engine (CU-Jet) has been provided in Figure 3.

Insert Figure 3

\subsubsection{Aircraft level performance analysis}

The performance of the CU-Jet engine was interpreted over a user-defined flight trajectory in an effort to measure mission based fuel consumption for each of the Bio-SPKs. In order to achieve 
this objective, a model aircraft, (LokAir) equipped with two CU-Jet engines, was numerically developed. The purpose of this assessment is to quantify and compare fuel usage incurred with each of the Bio-SPKs against Jet-A, on a fixed flight profile. The range of mission was fixed at 4650 $\mathrm{km}$, a typical mission range similar to a flight journey between London Heathrow (LHR) to Bahrain International $(\mathrm{BAH})$. It is essential to note that the aircraft based geometric, weight and range specifications were adopted from that of a baseline (A321) with addition of assumptions for flight trajectory [43].

\subsection{Input Parameters and assumptions}

Engine performance analysis assumes that gas properties vary with operating conditions and the gas mixture behaves like partially perfect gas. HERMES, the aircraft performance simulation program adopted for this study, employs point mass based modelling which involves prediction of fuel consumption through computational analysis of the motion of the aircraft's centre of gravity (CoG) and measurement of mass change at each segment of user-defined trajectory. Other technical assumptions considered in the place of proprietary engine specifications have been tabulated in Table 5.

Insert Table 5

\subsubsection{System based Emission analysis- $\mathrm{CO}_{2}$ and NOx}

\subsection{Engine and Mission $\mathrm{CO}_{2}$}

$\mathrm{CO}_{2}$ and $\mathrm{H}_{2} \mathrm{O}$ are direct pollutants of any hydrocarbon combustion and thus, their quantifications are straight forward [Equation 12].

$$
C_{x} H_{y}+m_{s}\left(O_{2}+3.76 N_{2}\right) \rightarrow x C O_{2}+\frac{y}{2} H_{2} O+\left(3.76 . m_{s}\right) N_{2}
$$

where, $m_{s}=$ Stoichiometric moles of air (Oxidant)

The combustion temperatures for each of the Bio-SPKs were predicted using respective composition assuming that the hydrocarbons undergo complete combustion with air as the oxidant [Equation 13].

Fuel composition, fuel use for engine performance and aircraft operations over the mid-range trajectory, determined from earlier analyses were incorporated to determine the system level $\mathrm{CO}_{2}$ 
emissions of each of the fuel candidate. The outcome of this assessment has been presented in results and discussion section 4.9 .4

$$
C \mathrm{O}_{2_{\text {wake }}}=\frac{C C_{\text {fuel }}}{L H V_{\text {fuel }}} \times \frac{M m_{C O_{2}}}{M m_{C}}
$$

where, $\mathbf{C O}_{2_{\text {wake }}}=\mathrm{CO}_{2}$ emissions from the wake of an aircraft $\left(\mathrm{g} \mathrm{MJ}^{-1}\right.$ of fuel)

$\boldsymbol{C} \boldsymbol{C}_{\text {fuel }}=$ Carbon Content of the fuel (mole fractions)

$\boldsymbol{L} \boldsymbol{H V}_{\text {fuel }}=$ Lower Heating Value of the fuel $\left(\mathrm{MJ} \mathrm{g}^{-1}\right)$

$\mathrm{Mm}_{\mathrm{CO}_{2}}=$ Molecular mass of $\mathrm{CO}_{2}\left(\mathrm{~g} \mathrm{~mol}^{-1}\right)$

$\mathbf{M m}_{C}=$ Molecular mass of Carbon $\left(\mathrm{g} \mathrm{mol}^{-1}\right)$

\subsection{Engine and Mission NOx}

An elaborate stirred reactor model was adopted and used to computationally quantify NOx attributable to each of the Bio-SPKs, as suggested by earlier studies [35] \& [36]. Emission indices predicted for the biofuel candidates where interpreted to mission level emissions using individual fuel consumption patterns for LokAir-C, LokAir-M and LokAir-J (across the user-defined mid-range trajectory. Combustor reactor dimensions and compartment characteristics have been detailed in Appendix Q. [Note: LokAir is the model aircraft equipped with two CU-Jet engines. LokAir-K, LokAir-C, LokAir-M and LokAir-J are the model aircraft operated with Jet-A, Camelina SPK, Microalgae SPK and Jatropha SPK respectively. NOx prediction has been conducted at throttle settings related to the Landing-Take off (LTO) cycle. However, NOx has been predicted for operation at cruise mode as well. The ICAO prescribed method of EI NOx prediction and comparison, at prescribed engine settings and time in mode have been provided in Table 6 .

Insert Table 6

\subsubsection{Life Cycle processes of Conventional Jet-A}

The Life cycle processes and emissions of conventional Jet-A have been adopted from earlier studies [46], [47] \& [48]. However, the life cycle inventory was reconstructed and the emissions have been recalculated through incorporation of technology efficiency improvement of $11.1 \%$ achieved over the last 40 years, as suggested by an earlier study [46]. The $\mathrm{CO}_{2}$ equivalent of life 
cycle GHG emissions from Jet-A was determined to be $105.0 \mathrm{~g} \mathrm{MJ}^{-1}$ of Jet-A. Further details on the assumptions and the life cycle process of Jet-A can be obtained from Appendix $\mathrm{H}$.

\section{RESULTS \& DISCUSSION}

\subsection{Chemical Composition of Bio-SPKs}

The "Drop-in" nature of the Bio-SPKs implies that they can be incorporated in their pure composition into existing engines without the need for modifications to engine configuration. An airline industry is sensitive to two main factors: technology/maintenance cost and passenger safety. In this context, fuel choice is of greater significance as an incompatibility could only prove to be cumbersome, demanding redesign and optimisation of the entire engine scheme. This could lead to increased maintenance cost and passenger safety concerns. There are inter-continental regulatory bodies that set strict standards and specifications for aviation fuel for commercial purpose, upon visual, laboratory and site based evaluations. Some key examples of these authorities are ASTM (American Standard for Testing and Materials) and DEF-STAN (UK Defence Standards).

Novel alternative fuels that are aimed for aviation purposes have to pass through a series of standard assessment to be qualified for their commercial use. The low aromatic content of pure Bio-SPKs is one among the most scrutinised features and its significance to operation and performance of an integrated system is discussed below.

The aromatic content of a fuel causes the rubber seals used in the high pressure fuel system to swell thus preventing fuel leaks during operation at various altitudes. Therefore, ASTM specifies that aviation fuels must contain a minimum of $8 \%$ by volume of aromatics towards qualification for commercial use. Bio-SPKs contain very less or no aromatic content in them which is advantageous from the environmental perspective (low volatile organic compounds). This may prove to be disadvantageous to Bio-SPKs since its pure use may cause fuel leaks and coke depositions resulting from kinetic heating and eventually higher maintenance costs. However, the newer fleet of aircraft may be constructed with commercially feasible "state of the art" hardware specifications which could be biofuel compatible. It is essential to note that the fuel specifications are fuel 
standards generalised towards global fleet of carriers. In view of such compatibility issues and subsequent safety issues, Bio-SPKs have been currently restricted to $50 \%$ blends with conventional aviation fuel for commercial use. The double-rings in the aromatics become unstable upon prolonged exposure to varying temperatures degrades and results in the formation of "gums" which settles in the fuel tanks and fuel line obstructing fuel flow [42]. In positive terms, lack of aromatics in the Bio-SPKs provides them ideal storage and handling specifications. These fundamental standards and specifications for the aviation fuels are currently under review and will be revived towards the newer fleet of aircraft to pave way for deserving sustainable aviation fuels. Other fuel parameters of performance significance have been discussed in Appendix I for reader's reference

\subsection{Direct and Indirect Land use change}

Land use change is one of the emission contributing factors associated with biofuels and is also a hotly debated uncertainty for consideration. Emissions from land use change are scaled based on the area of land used and its fertility factor. However, in many studies, the feedstock chosen for this analysis have been determined to perform well in marginal land [7], [8], [9], [12], [13] \& [16] and thus eliminate the risk of "food vs. fuel" conflict.

Camelina sativa, in this study, have been assumed to be crop rotated with Winter wheat which can be expected to contribute to indirect Land use change (iLUC). However, the iLUC emissions have been excluded in this study owing to the biofuel crop's ability to improve soil quality over its life time. Cultivation of microalgae is independent of arable land requirement as a result of which LUC emissions are eliminated in this scenario. Cultivation of Jatropha curcas on non-arable land has been demonstrated to reclaim waste land. Bailis and Baka, [24], have assumed this scenario to contribute to emissions from indirect land use change. However, these emissions have been omitted since it is outside the scope of this study.

\subsection{Biomass cultivation}

Biomass cultivation was observed to be the second highest contributor to the LCE of Bio-SPKs. Emissions related to overall biomass cultivation arise from soil preparation, fertiliser/ nutrient application and water supply. Regional carbon intensity attributable to each of the fertilisers used in 
the cultivation process have been accounted, unlike average and standardised figures used in existing LCE models. Emissions related to fertiliser/ nutrient use were observed to be significant and cultivation of microalgae was determined to be carbon intensive relative to Camelina and Jatropha. Nitrogen based fertilizers contribute the highest GHG emissions due to $\mathrm{N}_{2} \mathrm{O}$ emissions emanating from mineralization of nitrogen in the soil. These observations were the result of requirement of high quality nutrients and relatively higher fresh water demand for culture and regular top-up of evaporated medium. Camelina sativa, owing to its lesser demand for irrigation, produced the lowest of water supply emission. Abou Kheira and Atta, [49], observed that Jatropha trees treated with increased water supply performed well, in terms of seed quality and oil content. However, the balance between improved plant productivity and water supply emissions is an aspect that requires further study. GHG emissions attributable to quantified energy and resource inputs have been computed and the outcome has been presented in Table 7 .

Insert Table 7

\subsection{Biomass Credit}

Biofuel plantations enable natural carbon sequestration through photosynthesis. Biomass derived carbon deficit is allocated to a product or a process depending upon its capacity to sequester $\mathrm{CO}_{2}$ (atmospheric and anthropogenic) during its life cycle. This allocation of $\mathrm{CO}_{2}$ equivalent LCE-offset is also expressed as $\mathrm{g} \mathrm{MJ}^{-1}$ of fuel product.

Zhang et al, [50], have reported that Camelina sativa $\mathrm{CO}_{2}$ has a carbon fixation rate of an average of $3.1 \mathrm{MT}$ ha ${ }^{-1} \mathrm{yr}^{-1}$. This data was interpolated into this analysis and the $\mathrm{CO}_{2}$ equivalent $\mathrm{GHG}$ offset (biomass credit) apportioned to Camelina SPK was determined to be $70 \mathrm{~g} \mathrm{MJ}^{-1}$ fuel. Carter et al, 2012, stated that microalgal biomass requires a $\mathrm{CO}_{2}$ supply of twice its dry cell weight. An average of $1200 \mathrm{ppmv}$ of $\mathrm{CO}_{2}$ supply has been recorded to be sufficient to improve biomass productivity [27] \& [30]. Thus, the biomass credit allocated to Microalgae SPK was determined to be $71.5 \mathrm{~g} \mathrm{MJ}^{-1}$ of fuel. With respect to Jatropha curcas, Firdaus et al, [51], and Romijn H.A, [51], have experimentally determined the capacity of a 3 year old plantation to sequester an average of 13 tons $\mathrm{CO}_{2} \mathrm{ha}^{-1}$ per annum. This data led to the allocation of a carbon credit of $70.0 \mathrm{~g} \mathrm{CO}_{2} \mathrm{MJ}^{-1}$ for Jatropha SPK. 


\subsection{Biomass Harvest}

The emissions associated with Camelina seed harvest results from use of LS diesel for harvesting. Microalgal biomass, owing to its microscopic structure, has to be centrifuged thoroughly during the dewatering process. The energy intensity of biomass harvest is variable with the morphology of the feedstock microalga. Carter et al [10], have assumed and electric electricity supply of an average of $1.07 \mathrm{kWh} \mathrm{kg}^{-1}$ biomass for baseline scenario which has been adopted for this study. Jatropha seeds are harvested manually and therefore do not incur any $\mathrm{CO}_{2}$ emissions.

\subsection{Feedstock and Bio-SPK Transportation}

The assumptions considered earlier resulted in $\mathrm{CO}_{2}$ equivalents of standard transportation based GHG emissions of $0.067 \mathrm{~kg} \mathrm{~kg}^{-1}$ of LS diesel. Initially, the emissions related to transportation of each feedstock type have been calculated using the specific energy of total SPK obtainable from a hectare of land. The method of estimating this parameter has been has been presented earlier.

The calculated Bio-SPK transportation emissions have been determined to be higher than the values calculated in previous work. The reasons this discrepancy may be due to assumptions of similar fuel properties between Bio-SPK and the standard fuel by earlier studies thus using transportation emissions related to conv.jet fuel.

\subsection{Bio-crude Extraction}

The lipid content within the biomass is extracted using the solvent $n$-Hexane. Emissions from $n$ Hexane occur through vent losses upon reaction of the solvent with crushed mix of lipids and seeds/biomass. The by-products generated at this stage include seed/biomass cake. The seed cake and husk meal generated from Jatropha are poisonous and can potentially be used as biomass for direct combustion. Emissions related to hexane use were fairly equal with each of the feedstock because these emissions depended upon the degree of biomass yield and total obtainable SPK energy obtainable from the same. These $\mathrm{CO}_{2}$ equivalent $\mathrm{GHG}$ emissions fell in the range of $0.45-0.5 \mathrm{~g} \mathrm{MJ}^{-1}$. 


\subsection{Hydroprocessing}

Bio-SPK is synthesised through Hydrotreatment process which results in the production of different distillates including renewable jet fuel (Bio-SPK) and renewable diesel. From the knowledge of the Hydrotreatment process illustrated, it is evident that air emissions released from the process include $\mathrm{CO}_{2}$ from decarboxylation and $\mathrm{NOx}$ emissions from the hydrogenation step. However, the amount of GHG released at each stage is unknown due to lack of information in open literature. The final products of Hydrotreatment comprises $70 \%$ of renewable jet fuel, $15 \%$ of renewable diesel and the rest of the fraction is made of lighter liquid and gaseous products. The $\mathrm{CO}_{2}$ equivalent of net GHG emissions arising from Hydrotreatment to produce individual Bio-SPK types is assumed to be $10.3 \mathrm{~g} \mathrm{MJ}^{-1}$ of the fuel product similar to earlier life cycle analysis [12], [15] \& [14].

\subsection{Bio-SPKs combustion}

Fuel Combustion is the phase which contributes that highest GHG emissions in terms of "CradleGrave" emission assessment. Therefore, it is imperative to predict this phase with utmost accuracy. The route of fuel utilisation, combustion and release of wake emissions have been directed through computation modelling and real-time, non-linear simulation to best imitate an experimental setup. The model developed have been cross-checked and validated with existing commercial benchmark model (Twin shaft turbofan engine- CFM56-5B/2; Airframe- A321-100; Mid-range missions London, Heathrow [LHR] to Bahrain International [BAH]). The outcome of the analysis has been directed in the technical order listed below from subsections 4.9.2-4.9.4.

\subsubsection{Fluid Properties of Bio-SPKs}

Key thermodynamic properties which influence gas turbine performance were determined for each of the Bio-SPKs using NASA CEA's seven term functions [38]. The gas properties were determined to behave in synonymy with Jet-A. However, slight differences in the $\mathrm{H} / \mathrm{C}$ ratio among the candidate fuels have resulted in minor variations in certain gas properties. The $\%$ differences encountered with the thermodynamic properties between the biofuels and reference fuel have been presented in Figure 4. The effects of dissociation have been clearly exhibited. For instance, with Isobaric specific heat, the degree of energy release (Enthalpy) from transitional, rotational and vibrational modes of molecules in the fuel air mixture increases with fuel air ratio. The relationship 
between enthalpy $(h)$ and isobaric specific heat $(\mathrm{Cp})$ can be presented with the fundamental definition for enthalpy [Equation 14].

$$
H=d H+\int C p d T
$$

The ability of higher hydrogen content to counter the effects of dissociation is well acknowledged and can also be understood through the relationship between enthalpy and equation of state [Equation 16]

$$
\begin{aligned}
h & =e+p v \\
p v & =R T \\
\therefore h & =e+R T
\end{aligned}
$$

Insert Figure 4

With respect to gas constant $(R)$, gas mixtures (at very high temperatures) containing increased quantities of dissociated products are likely to contain a lower molecular mass (Mm). Gas constant (R) of the given gas mixture is therefore influenced with the level of dissociation through Equation 7

$$
\boldsymbol{R}=\frac{\boldsymbol{R}_{\text {universal }}}{M m}
$$

It is quite evident from Figure 4 that the thermodynamic behaviour of the Bio-SPKs is not identical to Jet-A. These variations are likely to have a marked effect within an operational gas turbine engine and its subsequent performance delivery. The fluid thermodynamic library developed for each of the Bio-SPKs was implemented into the gas turbine simulation software towards the upcoming task of studying fuel impact on engine behaviour. The new thermodynamic model was required to be verified in terms of precision with that of industrial standard NASA CEA. Isobaric specific heat capacity $(\mathrm{Cp})$ was chosen as the fluid property for verification since the fundamental definitions for fully-rigorous calculation of enthalpy and entropy contain integrations of $\mathrm{Cp}$. The \% difference in estimated $\mathrm{Cp}$ between the two thermodynamic models for each of the Bio-SPKs was determined to be $<0.015 \%$ between temperature ranges of $200-3000 \mathrm{~K}$. It is essential to note that the accuracy of fluid property prediction is also dependent on a key parameter, the fuel composition. 


\subsubsection{Engine performance analysis}

CU-Jet, when operating with the reference fuel (Jet-A), was matched with the baseline engine, (CFM56-5B/2) at design point (Cruise), off-design conditions (take-off and top of climb). The parameters of engine matching and validation are net thrust and SFC. The validity threshold was set at $<1 \%$ for design point Table 8 .

Insert Table 8

It is essential to note that the net thrust was maintained constant to amplify the fuel consumption parameter. Specific fuel consumption (SFC) related to the Bio-SPKs from representative engine operating at Take-off, climb and cruise mode was obtained from computational analysis and have been presented in Appendix N- Appendix P.

Specific Fuel Consumption of the CU-Jet-C, CU-Jet-M, CU-Jet-J operated with Camelina SPK, Microalgae SPK and Jatropha SPK was determined to be reduced by $2 \%, 1.3 \%$ and $2 \%$ respectively relative to Jet- $\mathrm{A}$. The higher $\mathrm{H} / \mathrm{C}$ ratio of the biofuels and its subsequent effect on the fuel caloric property (improves energy content) was determined to influence as a reduction in fuel flow which in turn reflected on respective fuel operated engine SFCs.

\subsubsection{Flight mission analysis}

The purpose of this analysis was to quantify and compare any fuel savings obtainable from each of the biofuels against the standard Jet-A, over a user-defined flight profile. The model aircraft (CUJet-K) was validated against that of its benchmark airframe (A321-100) through payload range comparison [43]. The \% difference in payload-range characteristics between the two models were restricted to $<2 \%$.

Insert Figure 5

Fuel savings for the mid-range trajectory, offered by the Bio-SPKs were determined to be the following; $-3.8 \%$ for Camelina and Jatropha SPK and $-3.1 \%$ for Microalgae SPK relative to Jet-A. It is essential to note that mission fuel burn was recorded for a fixed flight range for all the three BioSPKs as presented in Figure 6. 
Insert Figure 6

\subsubsection{System Emissions analyses- Mission $\mathrm{NOx} \& \mathrm{CO}_{2}$}

The demand for an alternative fuel source stems from the requirement of two key factors;

sustainability and emission reduction. Considering the Life Cycle (cradle-grave) emissions analysis, engine based emissions contribute to $\approx 70 \%$ of overall life cycle emissions of any given fuel. Therefore, careful estimation of engine based emissions is an important to estimation of total life cycle emissions.

\subsubsection{Engine and Mission $\mathrm{CO}_{2}$}

$\mathrm{CO}_{2}$ emission released from LokAir-C, LokAir-M, LokAir-J (modelled aircraft operating with Camelina SPK, Microalgae SPK and Jatropha SPK respectively) was determined to be 71.0, 72.0 and $70.6 \mathrm{~g} \mathrm{MJ}^{-1}$ respectively. Similar to NOx emissions, total mission $\mathrm{CO}_{2}$ was calculated from the amount of fuel consumed, by corresponding fuel variant aircrafts, at every phase of the flight trajectory and presented in Figure 7.

Insert Figure 7

The reductions in $\mathrm{CO}_{2}$ emission at aircraft operation is the result of a twin effect of lower carbon content and lower FAR of the Bio-SPKs relative to that of Jet-A. Variations in predicted fuel consumption among the fuel candidates and subsequently derived engine emissions have been tabulated in Table 9.

Insert Table 9

However, from mission perspective, the $\%$ average reduction in $\mathrm{CO}_{2}$ emissions across the midrange trajectory, attributable to modelled aircrafts LokAir-C, LokAir-M and LokAir-J, were determined to be $6.2,5.8$ and 6.3 respectively. [NOTE: The three Bio-SPKs were computationally incorporated and tested on the same engine at individual scenarios for the purpose of uniformity of study. However, the significance of these outcomes can only be proved through an elaborate cost analysis which will shed light on fuel and emissions costs in greater detail. 


\subsubsection{Engine and Mission NOx}

The purpose of reporting NOx emissions attributable to the combustion of each of the Bio-SPKs is its inevitability and environmental impact at ground level and upper stratospheric layers of aircraft operation [35]. Validation of EI NOx for Bio-SPKs could be compared only with reference data mentioned above owing to the novelty of this analysis. EI NOx attributable to each of the fuel candidate, specific to the engine's power setting as guided by ICAO- LTO cycle specifications has been tabulated in Table 10 and schematically represented in Figure 8.

\section{Insert Figure 8 and Table 10}

The overall difference in NOx emissions from mission simulation of LokAir-C, LokAir-M and LokAirJ during the LTO cycle were determined to be $-8.1 \%,-7.7 \%$ \& $-8.3 \%$ relative to CJK, respectively. This outcome was also observed in synonymy with the experimentally predicted $\sim 1-5 \%$ reduction in NOx emissions observed from analysing $25 \%$ and $50 \%$ Jet-A blended Bio-SPKs [15] \& [17]. The significant of this reduction in NOx improved when accounting the complete mid-range missions when the NOx savings by LokAir-C, LokAir-M and LokAir-J were determined to be $18.1 \%, 15.9 \%$ and $18.9 \%$ respectively. Drop in fuel flow related to the Bio-SPKs over the LTO power settings $(100 \%, 85 \%, 30 \%$ and $7 \%$ engine power settings) was determined to be $-5.1 \%,-4.6 \%,-2.4 \%$ and $3 \%$ respectively. It is essential to note that these figures are related only to LTO cycle and does not include cruise conditions. However, the mission NOx for cruise mode has been presented in

\section{Figure 9.}

\section{Insert Figure 9}

The degree of NOx formation is influence by the fuel specific flame temperature which in turn is a function of FAR, fuel calorific value and isobaric specific heat as indicated by Borman and Ragland [56] in equation 18.

$$
T_{f}=T_{0}+\left(\frac{F A R}{1+F A R}\right)\left(\frac{L H V}{C p}\right)
$$

where, $T f=$ Flame Temperature, $K$

$$
\begin{aligned}
F A R & =\text { Fuel to Air Ratio } \\
L H V & =\text { Lower Heating Value of the Fuel, } \mathrm{kJ} \mathrm{kg}^{-1} \\
C p & =\text { Isobaric Specific Heat, } \mathrm{kJ} \mathrm{kg}^{-1} \mathrm{~K}^{-1}
\end{aligned}
$$


Bio-SPKs have an avg. of $2.5 \%$ higher energy content which is contributed by a $9 \%$ by mass increase in hydrogen. In addition to this feature, FAR stoic $_{\text {of }}$ Camelina SPK, Microalgae SPK and Jatropha SPK were determined to be $0.0665,0.0666$, and 0.0665 respectively as opposed to 0.068 for the reference fuel. Consequently, Bio-SPKs exhibit a lower flame temperature. Specific heat capacity of the fuel has also been determined to contribute to the fuel specific flame temperature by an earlier study [56]. From the gas property model, it will be evident that the Cp of Bio-SPKs is increased. Therefore, it can be safely said that the key factors contributing to lower flame temperature and thus lower NOx emissions of Bio-SPKs are lower FAR and higher LHV of the test fuel.

\subsection{Life Cycle GHG Emissions of Bio-SPKs}

From LCE point of view, the carbon intensity for Camelina SPK, Microalgae SPK and Jatropha SPK was determined to be lower than that of Jet-A, standard fuel. The LCEs of Camelina SPK, Microalgae SPK and Jatropha SPK were lowered by $71 \%, 57.5 \%$ and $64 \%$ respectively relative to Jet-A as presented in Table 11. This reduction was aided by carefully calculated rate of carbon fixation (biomass credit) performed by the biofuel plantations. Camelina SPK was able to exhibit the highest of saving in life cycle emissions due to its lessened need for water and fertiliser demand.

Insert Table 11

It is essential to note that the carbon content of the bio-crude and thus the Bio-SPKs was observed to be directly proportional to the capacity of the carbon fixation exhibited by the biofuel plantation, as observed from the ALCEmB method of biomass credit calculations. Rigorous research and development to improve the strain of biofuel feedstock for enhanced lipid storage and carbon sequestration capacities can be expected to have a marked effect on the chemical composition of the resulting biojet fuel. However, future development in the downstream techniques and Hydroprocessing technology may provide a solution and enable better control over fuel composition. 


\subsection{Co-Product Allocation \& Net energy ratio}

Mass allocation (ISO 14044) enables excess allocation of emissions to the comparatively higher number of co-products generated in the process of all the three feedstock. Mass based allocation reduces the $\mathrm{CO}_{2}$ equivalent of overall life cycle emissions of Camelina SPK, Microalgae SPK and Jatropha SPK to 24, 29, $29.5 \mathrm{~g} \mathrm{MJ}^{-1}$ of fuel, respectively. The reduction in LCE obtained with mass based allocation in comparison with energy based allocation for Camelina SPK, Microalgae SPK and Jatropha SPK was determined to be $-11.7 \%,-18.3 \%$ and $-17.3 \%$ respectively. Microalgae SPK benefited the most from mass based allocation due to its considerably higher biomass output and subsequent increase in carbon fixation rate.

The net energy ratio of Camelina SPK, Microalgae SPK and Jatropha SPK was determined to be 1.158, 1.135 and 1.164 as presented in Figure 10. The pattern of energy use between the BioSPKs has been fairly constant in all the life cycle stages except that of biomass harvest. The energy intensity of the harvest process varies with the morphology of biofuel feedstock [56]. Microscopic morphology of algal biomass thus demands high specification harvest equipment (disc centrifuge) which was determined to consume $1.62 \pm 0.5 \mathrm{kWh} \mathrm{kg}^{-1}$ algal biomass [10]. An increase in electricity consumed at this stage, relative to that spent on other feedstock, has led to drop in NER with Microalgae SPK. However, on an overall, all processes with were observed to be energy efficient (NER $>1$ ) with microalgae SPK and the other candidate biofuels as well.

Insert Figure 10

\section{CONCLUSION}

ALCEmB is a "Cradle-Grave" GHG emission prediction model devoted to advanced biofuels. Life cycle carbon savings delivered by $100 \%$ blends of Camelina SPK, Microalgae SPK and Jatropha SPK, from "cradle to grave" perspective, were determined to be $70 \%, 58 \%$ and $64 \%$ respectively. Among the Bio-SPKs, Camelina SPK had the lowest carbon intensity among the biofuel candidates. Camelina feedstock may appear to be an environmentally viable option. However, the natural carbon sequestration and waste land reclamation capabilities of Microalgae and Jatropha can have an equally significant positive impact coupled with improvement of social-economic conditions and energy independence of developing nations. The lower carbon content of the Bio- 
SPKs, in addition to improved calorific value delivered a positive impact as fuel savings (3.1-3.8\% relative to Jet- $A)$ at mission level performance. The higher hydrogen content $(2-2.5 \%$ relative to Jet-A) of the Bio-SPKs improved their combustion characteristics in terms of comparatively cooler adiabatic flame temperature which was reflected as reductions of significant reduction in mission NOx $(15-19 \%$ relative to Jet-A).

\section{FUTURE WORK}

This study will be succeeded by an elaborate cost assessment which will focus on the engine maintenance, fuel and emission costs associated with the Bio-SPKs in a comparative perspective against conventional Jet-A. This study is aimed at predicting the economic feasibility of the alternative fuels, in the context of production capacities adopted into ALCEmB, in comparison with the conventional Jet-A. This assessment is conducted through Direct Operating Cost (DOC) analysis of aircraft operated with the candidate fuels.

\section{ACKNOWLEDGEMENT}

This study was encouraged and driven to success with well-founded encouragement and support from Biofuels group at Cranfield University, Bedford. The support from staff and students including Hugo Pervier and Alex Nind is gratefully acknowledged.

\section{REFERENCES}

[1] Penner JE, Lister DH, Griggs DJ, Dokken DJ, McFarland M. Intergovernmental Panel on Climate Change (IPCC) Working Groups I and II- IPCC Special Report: Aviation and the Global Atmosphere: Summary for Policymakers [Internet]. IPCC, Geneva, Switzerland. 1999. [Cited 2012 Jan 06]. Available from: https://www.ipcc.ch/pdf/special-reports/spm/aven.pdf

[2] Kahn Ribeiro S, Kobayashis S, Beuthe M, Gasca J, Greene D, Lee DS, et al. Chapter 5: Transport and its infrastructure. In Climate Change. In: Metz B, Davidson OD, Bosch PR, Dave R, Meyer LA, editors. Contribution of Working Group III to the Fourth Assessment Report of the Intergovernmental Panel on Climate Change [Internet]. Cambridge: 
Cambridge University Press; 2007. [Cited 2012 Jan 06]. p. 325-385; Available from: http://www.ipcc.ch/pdf/assessment-report/ar4/wg3/ar4-wg3-chapter5.pdf

[3] Airbus. Airbus Press Centre. Airbus and Air Canada make North America's first ever "Perfect Flight" [Internet]. 2012 Jun 18. [Cited 2012 Dec 12]; [about 1 screen] Available from: http://www.airbus.com/presscentre/pressreleases/press-release-detail/detail/airbusand-air-canada-make-north-americas-first-ever-perfect-flight/

[4] ACARE. Advisory Council for Aviation Research and Innovation in Europe. Realising Europe's Vision for Aviation: Strategic Research and Innovation Agenda: Volume 1 [Internet]. 2012 Sept. [Cited 2014 Feb 02]; Available from: http://www.acare4europe.com/sites/acare4europe.org/files/attachment/SRIA\%20Volume\% 201.pdf

[5] Air Transport World. Canadian 100\% biofuel flight tests show significant emission reduction [Internet]. 2013 Jan 30. [Cited 2013 Feb 02]. Available from: http://atwonline.com/ecoaviation/canadian-100-biofuel-flight-tests-show-significant-emission-reductions

[6] Oil Price.com. China Eastern to run commercial flights on Biofuel [Internet]. 2013 Apr 25. [Cited 2013 May 30]; [about 1 screen] Available from: http://oilprice.com/Latest-EnergyNews/World-News/China-Eastern-Airlines-to-Run-Commercial-Flights-on-Biofuel.html

[7] Bernardo A, Howard-Hildige R, O'Connell A, Nichol R, Ryan J, Rice B, et al. Camelina oil as a fuel for diesel transport engines. Ind Crop Prod. 2003; 17(3):191-197.

[8] Krohn BJ, Fripp M. A life cycle assessment of biodiesel derived from the "niche filling" energy crop Camelina in the USA. Appl Energy. 2012 Apr; 92 (2012): 92-98.

[9] Shonnard DR, Williams L, Kalnes TN. Camelina-derived jet fuel and diesel: Sustainable advanced biofuels. Environ Prog Sustain energy. 2010; 29(3):382-392.

[10] Carter NA. Environmental and Economic Assessment of Microalgae derived Jet fuel. [Dissertation]. Cambridge (MA): Massachusetts Institute of Technology; 2012.

[11] Handler RM, Canter CE, Kalnes TN, Lupton FS, Kholiqov O, Shonnard DR, et al. Evaluation of environmental impacts from microalgae cultivation in open-air raceway ponds: Analysis of the prior literature and investigation of wide variance in predicted impacts. Algal Res. 2012; 1(1):83-92. 
[12] Sialve B, Bernet N, Bernard O. Anaerobic digestion of microalgae as a necessary step to make microalgal biodiesel sustainable. Biotechnol Adv. 2009; 27(4): 409-416.

[13] Khoo HH, Sharratt PN, Das P, Balasubramanian RK, Naraharisetti PK, Shaik S. Life cycle energy and $\mathrm{CO}_{2}$ analysis of microalgae-to-biodiesel: Preliminary results and comparisons. Bioresour Technol. 2011; 102(10): 5800-5807.

[14] Achten WMJ, Verchot L, Franken YJ, Mathijs E, Singh VP, Aerts R, et al. Jatropha biodiesel production and use. Biomass Bioenergy 2008; 32(12):1063-1084.

[15] Carter NA, Stratton RW, Bredehoeft MK, Hileman JI. Energy and Environmental Viability of Select Alternative Jet Fuel Pathways. 47th AIAA/ASME/SAE/ASEE Joint Propulsion Conference \& Exhibit; 201131 July- 3 Aug; San Diego, California: American Institute of Aeronautics and Astronautics. 2011.

[16] Stratton RW. Life cycle assessment of green House Gas emissions and non- $\mathrm{CO}_{2}$ Combustion effects from Alternative fuels. [Dissertation]. Cambridge (MA): Massachusetts Institute of Technology; 2010.

[17] Rahmes TF, Kinder JD, Henry TM, Crenfeldt G, LeDuc GF, Zombanakis P, et al . Sustainable Bio-Derived Synthetic Paraffinic Kerosene (Bio-SPK) Jet fuel flights and Engine tests program results. 9th AIAA Aviation Technology, Integration, and Operations Conference; 2009 Sept 21 - 23; Hilton Head, South Carolina, USA: American Institute of Aeronautics and Astronautics; 2009.

[18] McCall MJ, Kocal JA, Bhattacharyya A, Kaines TN, Brandvold TA, inventors; UOP LLC., assignee. Production of aviation fuel from renewable feedstock. United States patent US 8039682. 2011 Oct 18.

[19] Lokesh K, Prakash A, Sethi V, Goodger E, Pilidis P. Assessment of Life cycle emissions of Bio-SPKs for jet engines. ASME Turbo Expo 2013: Turbine Technical Conference and Exposition. Volume 2: Aircraft Engine; Coal, Biomass and Alternative Fuels; Cycle Innovations; 2013 Jun 3-5; San Antonio, Texas, US: ASME; 2013.

[20] Uryga-Bugajska I, Pourkashanian M, Borman D, Catalanotti E, Wilson CW. Theoretical investigation of the performance of alternative aviation fuels in an aero-engine combustion chamber. Proc IMechE Part G: J Aerospace Eng. 2011; 225(8): 874-885. 
[21] Visser W, Kluiters S. Modelling the effects of operating conditions and alternative fuels on Gas turbine Performance and emissions. Netherlands: Nationaal Lucht- en Ruimtevaartlaboratorium; National Aerospace Laboratory (NLR). Flight Division. 1998 Dec. Report No: NLR-TP-98629.

[22] Goodger EM, Ogaji SOT. Fuels and Combustion in Heat engines, 1st ed. Cranfield, UK: Cranfield University Press; 2011.

[23] Wong H. Life Cycle Assessment of Greenhouse gas emissions from Alternative jet fuels. [Dissertation]. Cambridge (MA): Massachusetts Institute of Technology; 2008.

[24] Allen DT, Allport C, Atkins K, Cooper JS, Dilmore RM, Drauker LC, et al. Propulsion and power Rapid Response Research and Development (R\&D) support: Advanced Propulsion Fuels research and development- Subtask: Framework and Guidance for estimating greenhouse Gas Footprints of Aviation fuels. Interim Report. Dayton $(\mathrm{OH})$ : The Aviation Fuel Life Cycle Assessment Working Group (US), Air Force Research Laboratory; 2009 Apr. Report No.: AFRL-RZ-WP-TR-2009-2206. Contract No: FA8650-08-D-2806-0011.

[25] Bailis RE, Baka JE. Greenhouse Gas Emissions and Land Use Change from Jatropha curcas - based Jet Fuel in Brazil. Environ Sci Technol. 2010; 44(2):8684-8691.

[26] Moser BR. Camelina (Camelina sativa L.) oil as a biofuels feedstock: Golden Opportunity or false hope? Lipid Tech. 2010 Oct 26; 22(12):270-273.

[27] Lupton FS, Traynor TJ, inventor; UOP LLC., assignee. Methods for producing hydrocarbon products from algal Biomass. United States patent US20110287503. 2011 Nov 24.

[28] Lal R. Carbon emission from farm operations. Environ Int. 2004; 30(7): 981-990.

[29] Kindred D, Berry P, Burch O, Sylvester-Bradley R. Effects of nitrogen fertiliser use on greenhouse gas emissions and land use change. In Halford N, Jones HD, Lawlor D, editors. Asp Appl Biol 88: Effects of Climate Change on Plants: Implications for Agriculture. 2008; p 536.

[30] Krishnamurthi V. Krishnamurthy Institute of Algology. Personal Communication; 2012.

[31] Rothausen SGSA, Conway D. Greenhouse-gas emissions from energy use in the water sector. Nature Clim Change [Internet] 2011. [Cited 2013 May 26]; 1(4): 210-219. Available from: http://www.nature.com/nclimate/journal/v1/n4/pdf/nclimate1147.pdf 
[32] Nelson GC, Robertson R, Msangi S, Zhu T, Liao X \& Jawajar P. Greenhouse Gas mitigation- Issues for Indian Agriculture [Internet]. New Delhi, India. International Food Policy Research Institute; 2009 Sept. [Cited 2012 May 26] pp 1-48. Available from: http://www.ifpri.org/sites/default/files/publications/ifpridp00900.pdf

[33] Sheehan J, Camobreco, V, Graboski,M Duffield,J, Shapouri,H. Life Cycle Inventory of Biodiesel and Petroleum Diesel for Use in an Urban Bus. Golden (CO): National Renewable Energy Laboratory; 1998 May. Report No: NREL/SR-580-24089.

[34] Hileman JI, Ortiz DS, Bartis JT, Wong HM, Donowhoo PE, Weiss MA, Waitz IA. Near-Term Feasibility of Alternative Jet fuels. Cambridge (MA): RAND Corporation. 2009. Report No.: PARTNERCOE- 2009-001. Sponsored by Federal Aviation Administration.

[35] Lefebvre AW, Ballal DR. Gas turbine Combustion. 2nd ed. Philadelphia: Taylor and Francis; 2010.

[36] Walsh PP \& Fletcher P. Gas Turbine Performance, 2nd ed. Oxford, UK: Blackwell Science Ltd; 2004.

[37] Bücker D, Span R, Wagner W. Thermodynamic property models for moist air and combustion gases. ASME: J Eng Gas Turb Power. 2003; 125(1):374-384.

[38] McBride BJ, Gordon S. Computer Program for Complex chemical equilibrium composition and application- User manual and Program description. Cleveland (OH): National Aerospace and Space Administration, NASA Glenn Research Centre Logistics and Technical Information Division; 1996 Jun. Report No.: NASA RP-1311-P2. Sponsored by National Aerospace and Space Administration.

[39] CFM International. The Technology behind CFM56-5B Turbofan engine [Internet]. 2014 [Cited 2013 May 15]; [about 2 screens]. Available from: http://www.cfmaeroengines.com/engines/cfm56-5b

[40] Department of Power and Propulsion. The TURBOMATCH Scheme, [Unpublished Manual]. Cranfield university, UK; manual provided at a lecture given 2012 Sept 06.

[41] Allaire DL. A Physics-Based Emissions Model for Aircraft Gas Turbine Combustors. [Dissertation]; Cambridge (MA); Massachusetts Institute of Technology; 2006.

[42] Laskaridis P. Performance Investigations of System Architectures for the more Electric Aircraft. [Dissertation]. Bedford, UK; Cranfield University; 2006. 
[43] Airbus. Airbus Technical data Support and Services. Airbus A321- Aircraft Characteristics Airport and Maintenance and planning [Internet]. 2012 Sept. [revised 2014 May 01; Cited 2014 Aug 24]. Available from:

http://www.airbus.com/fileadmin/media_gallery/files/tech_data/AC/Airbus-

AC_A321_May2014.pdf

[44] European Aviation Safety Agency. ICAO Engine Exhaust Emissions Data Bank - CFM565B/2 (Subsonic Engine) [Internet]. 2013 Apr 09. [Cited 2013 Apr 28]. [about 2 p.]; Available from: http://www.easa.europa.eu/system/files/dfu/2CM013\%20-\%20CFM565B2\%20\%2809.04.2013\%29.pdf

[45] Celis C. Evaluation and optimisation of environmentally friendly aircraft propulsion systems. [Dissertation]. Bedford,UK; Cranfield University; 2010.

[46] Koroneos C, Dompros A, Roumbas G, Moussiopoulos N. Life Cycle Assessment of Kerosene used in Aviation. Int J Life Cycle Ass. 2005; 10(6): 417-424.

[47] Lewis CA. (Energy Transport Support Unit, AEA Technology PLC).Fuel and Energy production and emissions factor. MEET Project: Methodologies for Estimating Air Pollutant Emissions from Transport. Final Report. European Commission. 1997 Jun; ETSU Report No. R112. Contract No. ST-96-SC.204.

[48] Skone TJ, Gerdes K. Development of Baseline Data and Analysis of Life Cycle Greenhouse Gas Emissions of Petroleum-Based Fuels. National Energy Technology Laboratory, Offices of Systems, Analysis and Planning. 2008 Nov. Report No: DOE/NETL2009/1346.

[49] Abou Kheira AA, Atta NMM. Response of Jatropha curcas L. to water deficits: Yield, water use efficiency and oilseed characteristics. Biomass Bioenergy 2009 Oct; 33(10):1345-1350

[50]Zhang Y, Yu L, Fu Yung K, Leung DYC, Sun F, Lim BL. Over-expression of AtPAP2 in Camelina sativa leads to faster plant growth and higher seed yield. Biotechnol Biofuels. 2012; 5(19): 1-10.

[51] Firdaus MS, Mohd Hanif AH, Safiee AS, Ismail MR. Carbon sequestration potential in soil and biomass of Jatropha curcas. 19th World Congress of Soil Science, Soil Solutions for a Changing World; 2010 Aug 1-6, Brisbane, Australia, International Union of Soil Sciences. 2012. 
[52] Romijn HA. Land clearing and greenhouse gas emissions from Jatropha biofuels on African Miombo Woodlands. Energy Policy 2011 Oct; 39(10):5751-5762.

[53] Lošák T, Hlusek J, Martinec J, Vollmann J, Peterka J, Filipcik R, Varga L, Ducsay L , Martensson A. Effect of combined nitrogen and sulphur fertilization on yield and qualitative parameters of Camelina sativa [L.] Crtz. (false flax). Acta Agr Scand Sect B Soil Plant Sci 2011; 61(4): 313-321.

[54] McVay KA, Lamb PF. Camelina Production in Montana [Internet]. 2008 Mar. [cited 2012 May 16]. [about 2 p.]; Available from: http://msuextension.org/publications/AgandNaturalResources/MT200701AG.pdf

[55] Ragozin NA. Jet Propulsion Fuels (translated by Jones WE), Translation editor: Mullins BP). Oxford, UK: Pergamon Press; 1996.

[56] Borman GL, Ragland KW. Combustion engineering. 1st ed. US: McGraw-Hill; 1998

[57] Chisti Y. Biodiesel from Microalgae. Biotechnol Adv. 2007; 25(2007): 294-301.

[58] Premalatha, M. CEESAT- Centre for Energy and Environmental Science and Technology, Trichy, India. Personal Communication; 2012.

[59]Zubr J, Matthäus B. Effects of growth conditions on fatty acids and tocopherols in Camelina sativa oil. Ind Crops Prod. 2002; 15(2): 155-162.

[60] Tikkoo A, Yadav SS, Kaushik N. Effect of irrigation, nitrogen and potassium on seed yield and oil content of Jatropha curcas in coarse textured soils of northwest India. Soil Tillage Res 2013; 134(0): 142-146.

\section{List of Tables}

\begin{tabular}{|r|l|}
\hline Table 1 & Molecular, Thermal, Physical and Chemical properties of Bio-SPKs and Jet-A \\
\hline Table 2: & GHG emissions from Process inputs \\
\hline Table 3: & Key Cultivation and Yield based assumption for each of the Bio-SPKs \\
\hline Table 4: & Temperature, Pressure and Other material specifications of Bio-crude Refining \\
\hline Table 5: & Design Based Inputs and Assumptions for CU-Jet Engine and Aircraft Model \\
\hline Table 6: & Typical LTO based emission prediction standards [[44]] \\
\hline
\end{tabular}


Table 7: $\quad$ GHG emissions from Energy and Material Inputs at Biomass Cultivation phase

Table 8: $\quad$ Validation of CU-Jet with CFM56-5B/2

Table 9: Comparison of $\mathrm{H} / \mathrm{C}$ ratio and Flight Missions Results (fuel burn \& $\mathrm{CO}_{2}$ emissions)

Table 10: El NOx emissions of candidate fuels at each of LTO engine settings

Table 11: Comparison of Life Cycle Emissions of Bio-SPKs against Conventional Jet-A

\section{List of Figures}

Figure 1: Distribution of Carbon species of Bio-SPKs

Figure 2: System Boundary of ALCEmB and Life cycle stages of the Bio-SPKs

Figure 3: General Schematic of modelled twin-shaft turbofan engine (CU-Jet)

Figure 4: \% Difference in FTPs between the Bio-SPKs and Jet-A

Figure 5: Payload-range characteristics compared between LokAir-K and A321-100

Figure 6: Mission fuel burn when operating LokAir with Bio-SPKs and Jet-A

Figure 7 Mission $\mathrm{CO}_{2}$ related to candidate fuels

Figure 8 Validation of model reactor and comparison of El NOx between candidate fuels operated on CU-Jet engine

Figure 9 Mission NOx related to candidate fuels

Figure 10: Net Energy Ratio vs. life cycle processes of the Bio-SPKs

\section{List of Appendices}

\begin{tabular}{|r|l|}
\hline Appendix A: & Estimation of Molecular Formula of Camelina SPK \\
\hline Appendix B: & Estimation of Molecular Formula of Microalgae SPK \\
\hline Appendix C: & Estimation of Molecular Formula of Jatropha SPK \\
\hline Appendix D: & Estimation of Molecular mass of Camelina SPK \\
\hline Appendix E: & Estimation of Molecular mass of Microalgae SPK \\
\hline Appendix F: & Estimation of Molecular mass of Jatropha SPK \\
\hline Appendix G: & Steps in Hydrotreatment of Bio-crude \\
\hline
\end{tabular}




\begin{tabular}{|r|l|}
\hline Appendix H: & Life cycle emissions of Conventional Jet-A \\
\hline Appendix I: & $\begin{array}{l}\text { Effects of Essential fuel properties on Engine performance - A qualitative } \\
\text { discussion }\end{array}$ \\
\hline Appendix J: & $\begin{array}{l}\text { Thermodynamic properties and combustion products generated for Jet-A using } \\
\text { NASA CEA }\end{array}$ \\
\hline Appendix K: & $\begin{array}{l}\text { Thermodynamic properties and combustion products generated for Camelina- } \\
\text { SPK using NASA CEA }\end{array}$ \\
\hline Appendix L: & $\begin{array}{l}\text { Thermodynamic properties and combustion products generated for Jatropha } \\
\text { SPK using NASA CEA }\end{array}$ \\
\hline Appendix M: & $\begin{array}{l}\text { Thermodynamic properties and combustion products generated for Microalgae } \\
\text { SPK using NASA CEA }\end{array}$ \\
\hline Appendix N: & $\begin{array}{l}\text { Off Design Analysis of CU-Jet engine at varying Altitudes and Ambient } \\
\text { Temperature conditions }\end{array}$ \\
\hline Appendix O: & Compressor Performance Analysis \\
\hline Appendix P: & $\begin{array}{l}\text { Comparison of Specific Fuel consumption of CU-Jet engine at Take-off, Climb } \\
\text { and Cruise mode operating with the three Bio-SPKs and Jet-A }\end{array}$ \\
\hline Appendix Q: & $\begin{array}{l}\text { Flight mode specific Engine Cycle parameters required for prediction of fuel } \\
\text { consumption }\end{array}$ \\
\hline
\end{tabular}




\title{
Life cycle greenhouse gas analysis of biojet fuels with a technical investigation into their impact on jet engine performance
}

\author{
Lokesh, Kadambari
}

Elsevier

Lokesh K, Sethi V, Nikolaidis T, Goodger E, Nalianda D, Life cycle greenhouse gas analysis of biojet fuels with a technical investigation into their impact on jet engine performance, Biomass and Bioenergy, Vol. 77, June 2015, pp. 26-44

http://dx.doi.org/10.1016/j.biombioe.2015.03.005

Downloaded from Cranfield Library Services E-Repository 